\title{
As potências políticas do deslocamento na etnografia, na tradução e na linguística
}

\author{
Evelyn Martina SCHULER ZEA ${ }^{1}$
}

${ }^{1}$ Universidade Federal de Santa Catarina (UFSC), evelynsz@gmail.com, Orcid.org/oooo0002-4213-6251 
RESUMO Junto ao sentido genérico de movimento, deslocamentos também sugerem, eventualmente, mudanças no movimento, movimentos no movimento, que podem levar a um lugar impensado ou, inclusive, situar algo fora do lugar. O texto que se segue foca neste modo imprevisível do movimento, priorizando correntes alternas em detrimento das contínuas, buscando dessa forma reativar os efeitos políticos talvez diminuídos em modalidades lineares. O seguimento destas potências políticas do deslocamento atravessa os campos da etnografia, da tradução e da linguística.

ABSTRACT Along with the generic sense of movement, dislocations also suggest, eventually, changes in movement, movements in movement, which can lead to an unimagined place or, even, situate something out of place. The text that follows focuses on this unpredictable mode of movement, prioritizing alternating currents to continuous ones, seeking in this way to reactivate political effects perhaps diminished in linear modalities. The following of these political potentialities of dislocations crosses the fields of ethnography, linguistics and translation. 
PALAVRAS CHAVE deslocamento. potências politicas. etnografia. tradução. linguística.

KEYWORDS dislocation. political potentialities. ethnography. translation. linguistics. 


\section{Introdução}

Na convocatória da Mesa-redonda intitulada "Políticas Linguísticas, Etnografia e Tradução"', a figura da política aparece adiante e isso se justifica por vários motivos. Entre eles, certamente os condicionamentos das posições e concepções políticas sobre as tarefas da linguística, da etnografia e da tradução. Sem deixar de levar em consideração tais condicionamentos, a minha contribuição para esta mesa procede de certo modo em sentido contrário. Pois o que aqui proponho é, em contrapartida, fazer uso de um direito à réplica diante os fatos e feitos da política. $E$ falo de réplica não no sentido de reprodução ou duplicação de posturas políticas, mas de interlocução com elas, ou seja, no sentido quase esquecido de interlocução como intervenção com efeito de interrupção e impugnação.

Já esta reatividade, se podemos chamá-la assim, me parece que responde estreitamente a modos de interação que aparecem em primeiro plano no trabalho etnográfico, onde permanentemente somos atingidos pelas alteridades com as quais lidamos. De modo que a réplica à política não resulta arbitrária nem opcional, mas exterioriza dinâmicas horizontais imanentes tanto às abordagens das ciências humanas quanto a seus objetos, que certamente nunca são meramente objetos, de estudo. Acredito que esse momento de reatividade ou, se preferirem, de interatividade seja tão destacado na linguística como o é na tradução. Posso ratificá-lo, de minha parte, na etnografia, da qual se pode dizer que vive precisamente dessa réplica ou interpelação reversa, isto é, da receptividade e elaboração dos impactos ou repercussões do pensamento dos Outros sobre seus conceitos e procedimentos. A tal ponto que se pode dizer sem intromissão nem permeabilidade, a etnografia simplesmente não é nada.

\footnotetext{
${ }^{1}$ No "II Seminário de Políticas Linguísticas Críticas", realizado de 26 a 30/11/2018 na UFSC; cf. politicaslinguisticas.paginas.ufsc.br/ii-seminario-de-politicas-linguisticascriticas-26-a-30112018/.
} 
Do que gostaria de tratar aqui - e obviamente apenas no sentido de ensaiar alguns passos - é do fator ou dos fatores políticos com os quais lidamos reiteradamente em nossas pesquisas; concretamente, vou comentar a potência política de um motivo que me parece atravessar os campos da etnografia, da tradução e da linguística. Este motivo, ao mesmo tempo precursor e condutor, é a figura do deslocamento.

\section{Deslocamento na etnografia}

Múltiplos e diversos são os sentidos do deslocamento na etnografia. Alguns deles resultam inclusive óbvios, como aquele em sentido espacial, mesmo quando a emergência de uma antropologia nativa ${ }^{2}$ já coloca em dúvida o alcance deste parâmetro. Menos óbvio é talvez o fato de que os sujeitos aos quais a etnografia tenta conseguir uma via de acesso parecem deslizar-se uma e outra vez como se buscassem preservar sua alteridade, suas diferenças, além de toda tentativa de captura ou fixação.Éo que experimentei, por exemplo, durante minha pesquisa de campo ${ }^{3}$ na aldeia waiwai de Jatapuzinho, em Roraima,

${ }^{2}$ Uma pesquisa antropológica nativa pode ser pensada como uma pesquisa que elabora uma dupla diferença, não apenas a diferença dos nativos com respeitos aos brancos ou vista por eles, mas crucialmente a diferença dos brancos com respeitos aos nativos, ou seja, de acordo com os critérios nativos. O que permite reformular questões como, por exemplo, as de conceito ou de território. Enquanto que no marco da primeira diferença se debate o estatuto dos conceitos indígenas ou do território indígena como propriedade, isso não impede que persistam no marco da segunda diferença outros critérios e modos de concepção. De tal forma que poderia se dizer simultaneamente que o que diferencia os brancos dos nativos são os sonhos, enquanto que o que diferencia os nativos dos brancos são as fricções que dizem respeito ao conceito ou à propriedade. Uma pesquisa antropológica nativa desenvolveria, portanto, menos uma antropologia alternativa que uma dupla estratégia antropológica.

${ }^{3}$ Realizei trabalho de campo com os Waiwai durante minha pesquisa de doutorado entre 2001 e 2005, com bolsa do SNF (Schweizerischer Nationalfonds), e durante minha pesquisa de pós-doutorado entre 2007 e 2008, com bolsa da FAPESP (Fundação de Amparoà Pesquisa do Estado de São Paulo). Os 'Waiwai' (ou 'Wai Wai' ou 'Uai Uai') encontram-se dispersos em extensas partes da região das Guianas e são falantes, em sua maioria, da família linguuística Karib. Constituiram-se a partir de processos seculares de troca e de redes de relações com 
onde no momento de fazer uma cartografia das famílias percebi que sua genealogia remetia frequentemente a outros grupos: Mawayana, Xerewyana, Hixkaryana... e meu desconcerto diante dessa dispersão só se agudizava quando me era reiterado por parte de diversas famílias a indicação que apenas alguns poucos eram Waiwai de verdade, mas os vizinhos nem tanto. Aos poucos percebi que o que estava em jogo não era uma constituição por um modo de ser, mas por um modo de transitar, de deslocar-se e de fazê-lo de uma maneira idiossincrática. ${ }^{4}$ Como tentei mostrar em outra parte (SCHULER ZEA, 2006, 2008, 2010) como a trajetória digressiva dos rodeios aparece como forma distintiva de seu deslocamento e isso não apenas no sentido espacial, mas também conceitual.

Esse deslocamento nativo é que, ao mesmo tempo, pode provocar na etnógrafa (ou no etnógrafo) um deslocamento bastante mais significativo que aquele espacial. Porque se já a confrontação com alteridades portadoras de outras formas de falar e pensar põe um limite a qualquer pretensão de consistência, tanto mais desestabilizador resulta a confrontação com alteridades que parecem deslocar-se constantemente, ou seja, a constatação derivada de que os outros são sempre outros. Esta elusiva diferenciação, agora no sentido de diferir, ou seja, de uma reiterada suspensão, emite por um lado uma radiação dissolvente sobre as certezas da etnógrafa

outros ameríndios na região, sendo que alguns deles (tais como os Hixkaryana, Mawayana, Katuena, Karapayana, Taruma e Xerew, entre outros) vieram a co-residir com eles, formando as atuais "comunidades Waiwai” das três Terras Indígenas que abrangem parte dos Estados do Amazonas, Pará e Roraima no Brasil, a "Community Owned Conservation Area” (COCA) no Sul da Guiana e algumas poucas famílias que vivem nas aldeias Tiriyó no Suriname (maiores informações encontram-se no verbete que escrevi para a "Enciclopédia dos Povos Indígenas no Brasil”, do Instituto Socioambiental: http://www.socioambiental. org/pib/epi/waiwai/waiwai.shtm.

" Catherine Howard chegou a designar os Waiwai como "argonautas do Norte Amazônico" em função dos deslocamentos que realizam periodicamente nas expedições em busca do que chamam dos enîhni komo, dos povos não-vistos. Os deslocamentos destas expedições configuram o tema principal da sua tese de doutorado: "Wrought Identities: The Waiwai expeditions in search of the 'unseen peoples' in Northern Amazonia” (2001). 
(ou do etnógrafo), enquanto que por outro lado coloca para ela (ou para ele) o desafio de conseguir aproximações num contexto que é definitivamente de consistência cada vez menor e de leveza maior.

Por esse efeito desorientador, a confrontação inicial de alteridades se deixa transcrever em termos de efeitos e contraefeitos do deslocamento. Mais inquietante me parece, contudo, o que acontece com outro tipo de deslocamento num plano que podemos chamar de conceitual. Me refiro ao que geralmente é considerado por nós como um deslizamento não permitido, como produto de um erro categorial, "a categorial mistake": enquanto que, por outro lado, pelo lado nativo, esse deslocamento é visto de outra forma, como via ou rodeio indispensável. Vou dar um exemplo concreto a respeito:

Assisti há pouco tempo um documentário que indaga a escravidão nas plantações de café no Brasil através das sinuosidades das memórias familiares. ${ }^{5} \mathrm{O}$ documentário perseguia esses rastros obstinada e sensivelmente. Ao final da sessão, no entanto, uma pergunta ficou para mim suspensa, flutuando, talvez fora de lugar. Eu me perguntava: como chegar a sentir a escravidão numa xicara de café? Ou - por extensão - como chegar a perceber o genocídio congolês numa barra de chocolate belga?

Deveria ser possível, já que sãohistórias que se cruzam em mais de um ponto. Não digo que seja imperativo atender à essas ressonâncias, mas tampouco deveria ser negado para quem busca estes enlaces. Entre estas diferentes dimensões deveria haver uma passagem. E, no entanto, é provável que esta conexão seja desestimada na maior parte das vezes precisamente como um erro categorial, dizendo que se trata de experiências de ordem distinta: num caso uma experiência sensorial, do sabor, dos sentidos, e, no outro, do acontecer histórico - e que, por conseguinte, tais fatos transcorrem em planos ou

${ }^{5}$ Trata-se do documentário “Gilda Brasileiro - Contra o esquecimento", que foi exibido em outubro 2018 na Mostra Internacional de Cinema em São Paulo, cf. http://42.mostra.org/ br/filme/9472-GILDA-BRASILEIRO---CONTRA-O-ESQUECIMENTO. 
campos ou dimensões sem passagem entre si. Ou seja, acontecem em regiões conceitualmente descontínuas entre as quais inclusive os deslocamentos resultam improváveis.

Essas fronteiras, que delimitam espaços de pertença, seriam as mesmas que impossibilitariam o acesso a aproximações imprevistas ou improprias, ou seja, deslocamentos. O que certamente produz uma sensação de impotência, de fracasso. Nada se pode fazer diante esse impasse? Repito a pergunta: como chegar a sentir a escravidão numa xicara de café? Ou o genocídio numa barra de chocolate belga?

Há coisas que só se entende chorando, diz um poeta (EIELSON, 1997). ${ }^{6}$ E uma resposta indígena diante desse impasse poderia ser formulada consonantemente da seguinte maneira: Há coisas que só se entende sonhando, sonhando-as.

Acredito nessa resposta mesmo sem pretender entender o acontecer do sonhar indígena: suas intrapolações, extrapolações e transpolações. O que sabemos é que o sonho é o trance da diferença, é o que faz a diferença entre brancos e indígenas. Nas palavras de Davi Kopenawa (2010, p. 581) no livro A queda do céu: “os brancos não sabem sonhar" , ou, como diz em outra parte, os brancos "dormem como machados abandonados no chão de uma casa" (2010, p. 52), o que sugere, além da pesada imobilidade, o simultâneo abandono da tarefa ou da arte de sonhar.

Vale lembrar também que Davi Kopenawa traça esta divisória do sonho em circunstâncias em que assistiu à uma série de imagens da destruição da floresta dos Yanomami. De tal forma que a incapacidade de sonhar é, segundo a formulação nativa, o que explica em ultima instancia a violência dos brancos contra o mundo.

Não vou entrar neste assunto profundo, desmesurado e crucial da potência dos sonhos indígenas. Certamente os relatos indígenas nos dão, a propósito, sinais de que os sonhos fornecem um desnível ou

${ }^{6}$ No poema Llanto obligado (ante una fuente de roma), que começa assim: Hay cosas que no compreendo/sino llorando... 
um duplo fundo por onde circulam humanos e não-humanos, os vivos e os antepassados, todos eles em mútua e incessante interpelação. De tal modo que já aí podemos distinguir o deslocamento como uma chave dinâmica e estrutural dos sonhos. Mas aqui apenas quero chamar a atenção para o deslocamento extremo que performa a fórmula Yanomami, dado que o que ela transmite ao mesmo tempo é que é a capacidade de sonhar, isto é, justamente essa atividade aparentemente tão leve e intangível, tão imprecisa e volátil, é ela, com toda a sua labilidade, a alternativa que os indígenas levantam contra a capacidade de destruição do mundo. De tal forma que, se os sonhos abrem um espaço de deslocamentos intensivos, eles mesmos aparecem na fórmula yanomami deslocando-se para transmutar o erro categorial na potência cosmopolítica.

Antes de prosseguir com a segunda parte da minha exposição, sintetizo mais uma vez meu propósito: o que tento é elaborar a partir de nossas práticas teóricas um dispositivo, neste caso, o do deslocamento, que nos permita entrar em interlocução com a política e replicar a ela. Essa reatividade não é insólita, mas, como apontei, um fator que atravessa o campo das ciências humanas - e não apenas elas.

\section{Deslocamentos na tradução}

Que a tradução possa ser concebida como um deslocamento não é, imagino, particularmente controverso. A questão é ver: de que magnitude é esse deslocamento? Até onde chegam os deslocamentos que ela produz? No que segue, vou tentar elaborar esta questão em dois casos concretos de tradução e fazer referência à uma passagem clássica da teoria da tradução para, em seguida, retomar o fator, já mencionado, da politicidade da tradução.

Um poeta escreveu um verso que continha esta palavra: bianchissimo, no sentido usual de um branco muito intenso. $\mathrm{O}$ 
tradutor do poeta - também poeta - se encontra com este termo que, à primeira vista, parecendo não revestir maior dificuldade, poderia ser traduzido para branquíssimo. Mas, então, ele toma uma decisão e traduz bianchissimo para weisser als weiss, (UNGARETTI; CELAN, 1997) ${ }^{7}$ - ou seja, para mais branco que branco. Essa tradução, acredito, produz um deslocamento que resulta tanto mais desestabilizador quanto imprevisto. Tanto assim que podemos nos perguntar, por exemplo, se a tradução mais branco que branco não tem o efeito de deslocar-nos para uma exterioridade descoberta e expor-nos à elas: pois mais branco que branco não nos fala mais de um branco ensimesmado, concentrado, mas da inquietude ou desassossego de um branco, de um branco fora de si mesmo, de um branco cuja branquidão- ou seja, sua suposta essência e identidade - saiu deslocado para fora de si e não lhe pertence mais.

Podemos ir mais longe seguindo este rastro, já que a tradução de mais branco que o branco mostraria que a tarefa de tradução não apenas permite esse deslocamento, mas que consiste nesse deslocamento. A tradução desloca enquanto aquilo que nos oferece não é a reprodução imaculada do original, não é secundar ao original em sua introversão, mas ao contrário motivar o que podemos chamar a extroversão do suposto original, que assim se transborda e escapa de si mesmo.

É precisamente o que acontece no significativo relato de uma tradução indígena evocada por José Ribamar Bessa Freire na UFSC durante um evento passado ${ }^{8}$. Alguns talvez vão lembrar desses versos em português e nheengatu:

\footnotetext{
${ }^{7}$ Trata-se da tradução feita pelo poeta Paul Celan dos versos do fragmento 24 de Todestraum (in: Merkbuch der Alten) do poeta Guiseppe Ungaretti (cf. Ungaretti \& Celan, 1997).

${ }^{8}$ No evento "Línguas, traduções e narrativas ameríndias" no dia 31 de outubro de 2013, na UFSC, cf. http://ppgas.posgrad.ufsc.br/2013/10/29/convite-para-ciclo-de-palestras-noppgas-lingua-traducao-e-narrativas-amerindias-com-joao-rivelino-rezende-barreto-ejose-ribamar-bessa-freire/.
} 
Te mandei um passarinho,

|patuá miripupé,|

pintadinho de amarelo,/

iporanga ne iaué.

Toda tradução é obviamente bilíngue, mas esta tradução o é também no sentido dos versos iniciais e o desafio consistia em verter estes versos em uma versão somente em português, isto é, traduzindo as linhas nheengatu na língua ao lado. A tradução foi feita em conjunto com um grupo de tradutores guarani e foram eles que descartaram a seguinte versão, aparentemente convencional:
Te mandei um passarinho
dentro de uma gaiolinha
pintadinho de amarelo
e bonito como você.

Pela seguinte versão:

Te mandei um passarinho

dentro de um cestinho, pintadinho de amarelo

e bonito como você.

A divergência estava, como se pode observar, na tradução de patuá mirim pela gaiolinha ou pelo cestinho, ou seja, na decisão de tirar o passarinho da gaiola e de colocá-lo num cestinho aberto. José Ribamar Bessa Freire conta esse processo com detalhes e agudeza (2009). Gostaria aqui apenas de chamar a atenção para o fato ou a impressão de que os tradutores guarani estejam falando através de suas figuras - de maneira reflexiva - ao mesmo tempo sobre 
as disjuntivas da tradução. Também para a tradução, com efeito, valem as alternativas seja de captura ou retenção, ou de abertura ou disposição para um eventual deslocamento e até iminente saída fora do lugar.

Mas, além disso, falo do abismo da tradução porque elaéa primeira a cair nela. A prova desse abismo, sua acreditação, é que também é um abismo para a mesma tradução. Isso é algo que podemos ver de perto em uma passagem clássica, talvez a mais citada da teoria da tradução, sobre o modo de concebê-la.

Me refiro ao texto de Roman Jakobson "Sobre os aspectos linguísticos da tradução” que propõe, como é bem conhecido, um esquema tríplice do qual formam parte a tradução intralinguística, a tradução interlinguística ou tradução propriamente dita, e tradução intersemiótica ou transmutação. Já o uso desta fórmula do que é propriamente dito no caso da tradução interlinguística sugere no esquema de Jakobson a ativa intervenção do próprio - isto é, da propriedade, do que constitui a propriedade - como critério determinante. Mas, além disso, a classificação de Jakobson se sustenta ela mesmo no pressuposto de delimitações e domínios linguísticos que são também funções da propriedade. Que essa demarcação é controversa mesmo a partir de uma abordagem linguística já foi sugerida, ao mais tardar, por uma anotação dos manuscritos de Saussure sobre a impossibilidade de determinar categoricamente, por exemplo, onde termina uma língua e começa outra - por exemplo, onde termina o português e começa o espanhol, quando o que prolifera na vida das línguas são antes incessantes deslizamentos.

Seria excessivo avançar aqui neste debate entre o efeito de desapropriação do deslocamento e a pressuposição de propriedade do esquema de Jakobson. Mas parece-me que a localização desta tensão sobre a questão da propriedade ou impropriedade da tradução 
é suficiente para sugerir em que sentido a questão da tradução pode ser radicalmente política: precisamente na medida em que localiza fora da política uma questão crucial para a política - como é a propriedade - da mesma forma que, como vimos, o tradutor localiza ou, se se pode dizer, des-localiza a brancura radical fora do branco.

A pressuposição de campos linguísticos descontínuos no esquema de Jakobson desliza aqui já para a terceira parte à respeito do deslocamento linguístico, que vou comprimir em um brevíssimo comentário de Saussure.

\section{Deslocamento na linguística}

Saussure enfatiza que na vida das línguas o que há é "transformação, ainda e sempre transformação" (SAUSSURE apud FEHR, 1997, p. 151). Tudo é transformação, não há significado, nem forma nem fala nem portanto linguagem - que permanecem as mesmas. Trata-se de uma transformação múltipla e incessante no tempo e no espaço, que faz com que a língua de hoje seja inevitavelmente diferente à de ontem ou à de amanhã - e ninguém poderia definir com precisão seus limites. A contraparte desta imprecisão é o fato de que a língua, como ressalta Saussure, "não morre por si mesma, não se extingue" (SAUSSURE apud FEHR, 1997, p. 254) e é, no que diz respeito a sua potencialidade, "imperecível" (unvergänglich) - ela apenas morre de morte violenta. Entre a vida e a morte das línguas o que há não é extinção, mas circularidade e interdependência, onde um se sustenta com o outro. No mais, uma língua não apenas se transforma linearmente, através de uma sucessão de estados alterados no tempo, mas, simultaneamente, ela também se fracciona em variações dialetais que se dispersam num espaço de crescente complexidade (cf. SCHULER ZEA, 2016). E o que produz esta transformação múltipla e incessante são os sucessivos deslocamentos que ocorrem 
na circulação das línguas, ou seja, um fator imanente à dinâmica das línguas. É por isso que ninguém poderia dizer com certeza qual é a fronteira entre português e espanhol, ou entre kaingang e laklãnõ, porque acontecem aí intermináveis deslocamentos.

Através destas breves incursões nos campos da etnografia, tradução e, muito de passagem, da linguística espero que seja possível, ao menos, vislumbrar algo da eficácia recorrente do fator de deslocamento, tanto na conformação do objeto e procedimento de estudo. Gostaria aqui apenas de indicar ainda a seguinte observação: os deslocamentos, obviamente, vêm da grande matriz do movimento, eles são uma modalidade sua, mas com uma ênfase particular no que não se encaixa e no intempestivos, no imprevisto, no inesperado. De tal modo que este dispositivo poderia ser provisoriamente formalizado nos seguintes termos: o surgimento de algo ou de alguém em outra parte, ou inclusive, fora de lugar.

Gostaria de finalizar aqui retomando o propósito anunciado inicialmente de replicar ou entrar em interlocução com a política a partir do dispositivo do deslocamento. Se trata de uma questão da política no sentido, por um lado, dos pressupostos políticos que condicionam a formulação de políticas específicas. Mas também se trata, por outro lado, da política no sentido comum ou aquela subjacente às interações sociais. Começo por esta última:

Nós todos ouvimos, desde criança, provavelmente, essa expressão: Ponha-se no seu lugar - que, enquanto faz referência a um lugar próprio e quase natural de pertença, expressa o oposto do que foi formulado sobre os deslocamentos. Eu não sei com que frequência ainda se segue falando dessa forma, mas segue vigente no léxico estabelecido. O dicionário Aurélio consigna no item 10 dos significados do lugar o seguinte exemplo:

10 Classe, categoria, ordem:

Ponha -se no seu lugar, não suporto má-criação! 
Ponha-se no seu lugar... Sempre - ou seja, na infância - essa expressão me perturbou: qual é o lugar de quem? Qual é o meu lugar? São perguntas que talvez devem ser reperguntadas, mas não para reiterar a distribuição nem apenas para redistribuir lugares, mas reperguntadas para questionar a pressuposição ideológica nessas perguntas de um lugar definitivamente próprio. O que tantas vezes não quer dizer reconhecer um lugar, mas impedir o deslocamento para outro lugar. E não apenas no plano das interações particulares, mas também aí onde uma sociedade decide sobre si mesma. Não são poucos os analistas, por exemplo, que examinaram os eventos políticos recentes em termos dos intensos deslocamentos sociais que ocorreram no país nas últimas décadas. Se colocou em questão suas dimensões e impactos, suas modalidades e como lidar com elas. Tanto assim que, para além das avaliações de cada parte, parecia haver concordância no debate sobre a conveniência ou não de tais deslocamentos.

Entre o plano das interações pessoais e o plano do das posições públicas, há outro plano dos deslocamentos que diz respeito à grupos vistos como minoritários, mesmo quando possam chegar a ser movimentos massivos. Um destes contingentes habitualmente inscritos entre os grupos minoritários é o dos migrantes. Eles são sujeitos de dramáticas noticias que chegam de diferentes partes do mundo e que converteram, entre outros cenários, o Mediterrâneo num cemitério marinho. Sabemos que imensas ondas migratórias também acontecem entre nós, nos países do Sul. Elas transportam pessoas com formas culturais e modos de expressão que demandam outras tantas tarefas de tradução. Chamar a atenção sobre esta dinâmica dos deslocamentos, sobre sua precariedade e sua potencia, poderia talvez contribuir a atenuar a indolência com respeito aos grupos minoritários. Poderia talvez chegar a ver-se que, tal como aconteceu com o genocídio dos indígenas ou com a escravidão dos 
negros, o porvir de um país está indelevelmente marcado pelo modo como são tratados os grupos minoritários e seus deslocamentos.

Ailton Krenak atenta sensivelmente para o modo como são tratados os grupos minoritários e seus deslocamentos e nos fala a respeito do "campo minado do exílio" (KRENAK, 2018, p. 8), onde cada "desterrado agora vai ter que reinventar ele e seu mundo" (2018, p. 11). O exílio induz a olhar para trás e refletir, tal como o faz Ailton Krenak. ${ }^{9} \mathrm{O}$ seguimento do deslocamento não deveria diminuir a atenção do drama e os desafios do campo minado do exilio. Mas a dupla composição do movimento - onde no mesmo momento alguém se distancia e se aproxima, alguém é expulso de um lugar e resistido em outro, demanda talvez refletir não separadamente, mas conjuntamente as alternativas do ir e do vir. ${ }^{10}$

\footnotetext{
${ }^{9}$ Há algo que pode parecer contingente ou meramente idiossincrático na figura de Ailton Krenak, mas isso também pode ser uma chave - em um sentido musical - para nos situar em outro registro. Me refiro a algo tão impreciso ou indeterminável como pode ser o rosto, o temperamento ou mesmo o timbre de uma voz. Marcas tênues de uma liderança que, no entanto, não deixam de ser eficazes, às vezes extremamente eficazes. Poderíamos fazer uma comparação com o que transmitem outras figuras: a exasperação de um candidato, a opacidade de outro, os cálculos de um terceiro ... e não deixaria de ter interesse, porque é parte subliminar da retórica da política. Mas bastante mais significativo é que essa irradiação transmite uma radicalização da política no sentido de sua excentração ou deslocamento radial para outras esferas, registros, dimensões ou mundos. Entendo nesse sentido o comentário feito por Ailton Krenak ao receber o doutorado Honoris Causa da UFJF: "Agora a gente precisa se radicalizar" (citado no filme: Ailton Krenak - O sonho da pedra, cf. Altberg, 2018).

${ }^{10}$ Sugiro ler e traduzir como tentativa de rastrear essa trajetória e alternativas do ir e do vir a seguinte passagem, na qual Alexis Nouss diferencia a figura do migrante e do exilado: "O migrante migra de um território a outro em função de uma identidade espacializada de acordo à uma ontologia cartográfica. $\mathrm{O}$ exilado passa de um céu a outro, de uma língua a outra, e retém na memória de uns e de outros fazendo-os dialogar" (NOUSS, 2015, p. 11.).
} 


\section{Referências}

ALTBERG, M. Ailton Krenak - O sonho da pedra. Documentário exibido no Canal Curta, cf. Disponínel em: http://canalcurta.tv.br/filme/?name=ailton krenak_e_o_sonho_da_pedra. Acesso em:30 jan. 2019.

EIELSON, J.E. Llanto obligado (ante una fuente de Roma), Habitación en Roma (1952). In: Poesía Escrita, Lima 1997.

FEHR, J. \& SAUSSURE, F. Saussure, Linguistik und Semiologie. Notizen aus dem Nachlass, Frankfurt: Suhrkamp, 1997.

FREIRE, José Ribamar Bessa. Tradução e interculturalidade: o passarinho, a gaiola e o cesto. Alea, Rio de Janeiro, v. 11, n. 2, p. 321-338, Dec. 2009. Disponível em: http://www.scielo.br/scielo.php?script=sci_arttext\&pid=S1517-106X20090 o0200010\&lng=en\&nrm=iso. Acesso em: 30 jan. 2019.

HOWARD, Catherine. Wrought Identities. The Waiwai expeditions in search of the "Unseen peoples" of Northern Amazonia. Tese (Doutorado em Antropologia) Universidade de Chicago, Illinois, 2001.

JAKOBSON, J. Aspectos Linguísticos da Tradução. In: Linguística e Comunicação. São Paulo: Editora Cultrix, 1973.

KOPENAWA, D.; ALBERT, B. La chute du ciel. Paroles d'un chaman yanomani. Paris: Plon, 2010.

KRENAK, A. A potência do sujeito coletivo - Parte I. Revista Periferias. Rio de Janeiro, v.01, n.o1, 2018. Disponível em: http://revistaperiferias.org/materia/apotencia-do-sujeito-coletivo-parte-i/. Acesso em:30 jan. 2019.

MANHÃES REIS, R. \& SCHEUERER, V. Gilda Brasileiro - Contra o esquecimento, documentário exibido em outubro de 2018 na Mostra Internacional de Cinema em São Paulo, cf. Disponível em: http://42.mostra.org/br/filme/9472-GILDABRASILEIRO---CONTRA-O-ESQUECIMENTO. Acesso em:30 jan. 2019.

NOUSS, A. La condition de l'exilé. Penser les migrations contemporaines. Paris: Maison des Sciences de l'Homme, coll. «Interventions », 2015. 
SCHULER ZEA, E. Metaphorisierte Umwege, uneigentliche Übersetzungen: Arbeit an Bildern im Doppelfeld der Waiwai-Anthropologie. Tese (Doutorado em Antropologia) - Universidade de Bern, 2006.

SCHULER ZEA, E. Genitivo da tradução. Bol. Mus. Para. Emílio Goeldi. Ciênc. hum. [online]. 2008, v. 3, n.1, pp.65-77. Disponível em: http://www.scielo.br/ scielo.php?script=sci_arttext\&pid=S1981-81222008000100006\&lng=en\&nrm =iso. Acesso em: 30 jan. 2019.

SCHULER ZEA, E. On -Yesamarî and Laterality: Waiwai Meanderings, Tipití: Journal of the Society for the Anthropology of Lowland South America: v. 8: Iss. 1, Article 2. Disponível em: https://digitalcommons.trinity.edu/tipiti/vol8/iss1/2. Acesso em: 30 jan. 2019.

SCHULER ZEA, E. Las dudas de Saussure: notas sobre la potencia de las disyunciones en la vida de las lenguas. Trad. Carolina Villada Castro. Linguistica e literatura. [online]. 2016, n.70, pp.193-203. Disponível em: http://www.scielo. org.co/scielo.php?script=sci_arttext\&pid=So120-55872016000200193\&lng=en \&nrm=iso . Acesso em: 30 jan. 2019.

UNGARETTI, G. \& CELAN, P. Das verheifsene Land. Das Merkbuch des Alten, Suhrkamp, 1997.

\section{Como citar}

SCHULER ZEA, Evelyn Martina. As potências políticas do deslocamento na etnografia, na tradução e na linguística. Revista da Abralin, v. 17, n. 2, p. 332-349, 2018. 